\title{
The adventurous way from feasibility to advisability
}

\author{
Tine Philipsen, MD, and Thierry Bove, MD, $\mathrm{PhD}$
}

\author{
From the Department of Cardiac Surgery, University Hospital of Ghent, Ghent, Belgium. \\ Disclosures: Authors have nothing to disclose with regard to commercial support. \\ Received for publication April 27, 2017; accepted for publication May 11, 2017; available ahead of print June 7, \\ 2017. \\ Address for reprints: Thierry Bove, MD, PhD, Cardiac Surgery Department, University Hospital Ghent, De Pin- \\ telaan, 185, Ghent 9000, Belgium (E-mail: thierry.bove@ugent.be). \\ J Thorac Cardiovasc Surg 2017;154:816-7 \\ $0022-5223 / \$ 36.00$ \\ Copyright $\subset 2017$ by The American Association for Thoracic Surgery \\ http://dx.doi.org/10.1016/j.jtcvs.2017.05.020
}

The advent of transcatheter aortic valve replacement (TAVR) undoubtedly has changed the perspectives on the management of high-risk patients with symptomatic severe aortic valve stenosis. ${ }^{1-3}$ A history of previous cardiac surgery may be considered a compromising factor, although a subgroup analysis within the Placement of AoRtic TraNscathetER Valves trial revealed that a surgical aortic valve replacement is still commendable after prior coronary artery revascularization, by showing a superior 2-year survival. ${ }^{4}$ Thus, in the landmark trials, the presence of previous mitral valve surgery was used as exclusion criterium. Meanwhile, major progress has been made, both in design and in experience, on the technical applicability of TAVR devices. In this issue of the Journal, Greason and colleagues ${ }^{5}$ focused on 18 patients in a series of 772 patients who had a TAVR after mitral valve annuloplasty in 4 and mitral valve replacement in 14 . In addition to some occasional reports, ${ }^{6-9}$ this study represents the largest singlecenter experience dealing with this specific condition. Both balloon- and self-expandable valve devices were used deliberately in the majority of patients through a transfemoral access. The landing zone between the native aortic annulus and the mitral prosthesis seemed to be noncritical, because even the absence of any safe distance appeared not to influence the success of the procedure or the functionality of the valves. Other questions of interest regarding anatomic boundaries remained unanswered, such as the optimal depth of device implantation in relation to the required radial forces during valve deployment, the effect of the angulation between the aortic annulus and mitral prosthesis, especially when concerning a bioprosthesis, and the potential impact of access to ensure maximal stability during prosthesis deployment. Overall, the procedural success was excellent, yielding few significant paravalvular leaks after TAVR and no damage to the mitral valve. Although repositionable valve devices might offer an additional advantage in this challenging condition, secondary repositioning of the device was necessary in only 1 case. Worth mentioning is the need for new permanent pacemaker implantation in one third of the patients, which is higher compared with the $6.7 \%$ to $19.7 \%$ after isolated TAVR ${ }^{10-12}$ and certainly replacement. $^{13}$

\section{References}

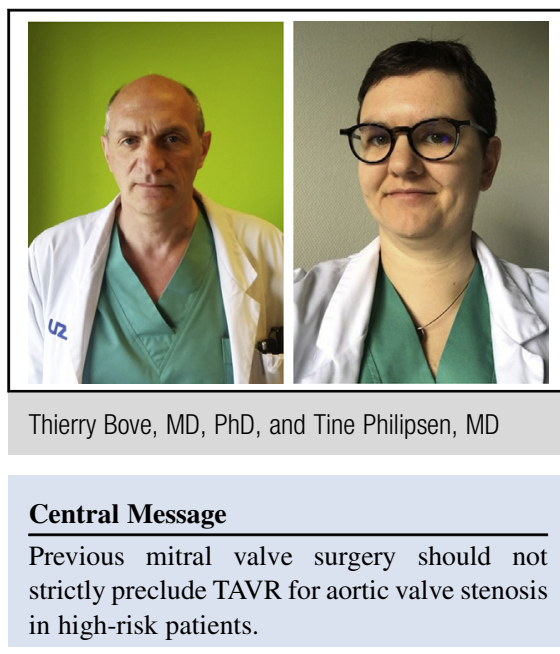

See Article page 810

than in combined surgical aortic and mitral valve

Unfortunately, despite their experience, the authors are not able to make some recommendations on the choice of particular prosthesis or the delineation of some preliminary guidelines for future procedures, retrieved from extensive multidisciplinary assessments of preoperative imaging. Therefore, according to their vague and meaningless suggestion that the selection algorithm is still attributed to the discretion of the heart team, the contribution of this work remains mainly limited to the notion that TAVR can be proposed as a feasible alternative to surgical aortic valve replacement in high-risk patients with aortic valve stenosis, even when they have a functional valve prosthesis in the mitral position. Usually, it is commendable that the boundaries of technical applicability of new therapeutic devices are explored. However, the authors have missed the opportunity to give some useful clues by which the chance to achieve a successful outcome with TAVR after previous mitral valve surgery, if done by less-experienced hands, surpasses the level of feasibility.

1. Smith CR, Leon MB, Mack MJ, Miller DC, Moses JW, Svensson LG, et al. Transcatheter versus surgical aortic-valve replacement in high-risk patients. New Engl J Med. 2011;364:2187-98.

2. Deeb GM, Reardon MJ, Chetcuti S, Patel HJ, Grossman PM, Yakubov SJ, et al. 3year outcomes in high-risk patients who underwent surgical or transcatheter aortic valve replacement. J Am Coll Cardiol. 2016;67:2565-74.

3. Adams DH, Popma JJ, Reardon MJ, Yakubov SJ, Coselli JS, Deeb GM, et al. Transcatheter aortic-valve replacement with a self-expanding prosthesis. New Engl J Med. 2014;370:1790-8. 
4. Greason KL, Mathew V, Suri RM, Holmes DR, Rihal CS, McAndrew T, et al. Transcatheter versus surgical aortic valve replacement in patients with prior coronary artery bypass graft operation: a PARTNER trial subgroup analysis. Ann Thorac Surg. 2014;98:1-8.

5. Greason KL, Sandhu GS, Nkomo VT, King KS, Joyce DL, Williamson EE, Holmes DR. Transcatheter aortic valve insertion after previous mitral valve operation. J Thorac Cardiovasc Surg. 2017; 154:810-5.

6. Bagur R, Kiaii B, Teefy PJ, Diamantouros P, Harle C, Goela A, et al. Transcatheter ACURATE-TA aortic valve implantation in a patient with a previous mechanical mitral valve. Ann Thorac Surg. 2015;100:e115-7.

7. Bruschi G, De Marco F, Oreglia J, Colombo P, Fratto P, Lullo F, et al. Percutaneous implantation of CoreValve aortic prostheses in patients with a mechanical mitral valve. Ann Thorac Surg. 2009;88:e50-2.

8. Dumonteil N, Marcheix B, Berthoumieu P, Massabuau P, Dieye E, Decramer I, et al. Transfemoral aortic valve implantation with pre-existent mechanical mitral prosthesis: evidence of feasibility. JACC Cardiovasc Interv. 2009;2:897-8.

9. Maluenda G, Caorsi C, Baeza C. Transfemoral implantation of CoreValve Evolut-R aortic prosthesis in patient with prior ball-cage mechanical mitral valve prosthesis. Cardiovasc Revasc Med. 2016;17:287-9.
10. Fadahunsi OO, Olowoyeye A, Ukaigwe A, Li Z, Vora AN, Vemulapalli S, et al. Incidence, predictors, and outcomes of permanent pacemaker implantation following transcatheter aortic valve replacement: analysis from the U.S. Society of Thoracic Surgeons/American College of Cardiology TVT Registry. JACC Cardiovasc Interv. 2016; 9:2189-99.

11. Kim WJ, Ko YG, Han S, Kim YH, Dy TC, Posas FE, et al. Predictors of permanent pacemaker insertion following transcatheter aortic valve replacement with the CoreValve revalving system based on computed tomography analysis: an Asian Multicenter Registry Study. J Invasive Cardiol. 2015. 27:334-40.

12. Nazif TM, Dizon JM, Hahn RT, Xu K, Babaliaros V, Douglas PS, et al. Predictors and clinical outcomes of permanent pacemaker implantation after transcatheter aortic valve replacement: the PARTNER (Placement of AoRtic TraNscathetER Valves) trial and registry. JACC Cardiovasc Interv. 2015;8: 60-9.

13. Leyva F, Qiu T, McNulty D, Evison F, Marshall H, Gasparini M. Long-term requirement for pacemaker implantation after cardiac valve replacement surgery. Heart Rhythm. 2017;14:529-34. 